\title{
Psychological reactions and coping strategies of Sri Lankan women carrying fetuses with lethal congenital malformations
}

\section{Hemantha Senanayake ${ }^{1}$, Damani de Silva ${ }^{2}$, Samanthi Premaratne ${ }^{3}$ and Manuja Kulatunge ${ }^{4}$}

(Index words: Need for counselling and legal reform, psychological distress)

\begin{abstract}
Introduction Termination of pregnancy is a popular option for pregnancies complicated by lethal congenital malformations (LCMs). In Sri Lanka, where abortion laws are restrictive, this is not available. We studied the psychological responses and coping strategies of women who had to continue their pregnancies knowing the baby had a LCM.
\end{abstract}

Setting A teaching hospital in Sri Lanka.

Study design Qualitative inquiry.
Method We conducted a semi-structured interview of 10 women whose fetuses were diagnosed to have a LCM.

Results All women showed a grief reaction on hearing the news and were distressed about having to carry a futile pregnancy. Eight women were grateful they knew of the abnormality because it prepared them for the birth better, while the other two wished they had not known. They all found having to share facilities with 'normal' women to be painful. Seven women who received 'routine' antenatal care felt that the doctors were ill-equipped to deal with their situation. All felt that abortion should be legalised for LCMs. All engaged in religious rites believed

${ }^{1}$ Senior Lecturer, Department of Obstetrics and Gynaecology, Faculty of Medicine, ${ }^{2}$ Senior Lecturer, Department of Psychological Medicine, Faculty of Medicine, University of Colombo, Sri Lanka; ${ }^{3}$ Senior Registrar, Professorial Obstetric Unit, De Soysa Hospital for Women, Colombo Sri Lanka; ${ }^{4}$ Senior Registrar, University Psychiatry Unit, National Hospital of Sri Lanka, Colombo, Sri Lanka.

Correspondence: HS, e-mail: <senanayakeh@gmail.com>. (Competing interests: none declared). 
to have miraculous powers, hoping that these will result in a normal baby. Two required specialised counselling.

Conclusions The diagnosis of a LCM causes severe distress and psychological reactions, which the staff dealing with these women should be aware of. Ideally, they should be provided care with minimum contact with other women, taking into account the futility of the pregnancy. Engagement in religious rites, even though with unreal expectations, may possibly help them in the long term bereavement process.

\section{Introduction}

The news of a lethal congenital malformation (LCM) in the fetus is devastating to the family. In countries where it is legal, termination of pregnancy is the usual course of action in this situation. A woman who is diagnosed as carrying a fetus with a lethal congenital abnormality could be asked to continue the pregnancy in a situation where the laws of the country do not permit termination of pregnancy. This is applicable in Sri Lanka. In addition, detection of abnormalities is often delayed due to the nonavailability of facilities for prenatal diagnosis, by which time the family has developed high expectations of the pregnancy and a deep attachment to the unborn child.

The psychological reactions and coping strategies of women in these situations do not receive adequate attention in Sri Lanka, because maternity care mainly emphasises the woman's safety and a satisfactory perinatal outcome. In this extremely difficult and traumatic time for the woman and her family, understanding the psychological response will enable care providers to help them cope better.

Similar situations have been studied in countries socio-culturally different from Sri Lanka, in women, who despite being offered a termination, opted to continue with their pregnancies [1-3]. Some of these have shown interesting findings. Women who continue these pregnancies may, in fact, recover faster from their emotional aftermath than its counterparts who had terminations [2]. Some women may not want to choose termination of pregnancy because they believe that the diagnosis possibly had an error in it $[1,3]$.

The aim of our study was to describe the psychological reactions and coping strategies of Sri Lankan women who were knowingly carrying fetuses with lethal congenital abnormalities.

\section{Method}

We conducted a qualitative inquiry in 10 women whose fetuses were diagnosed as having a lethal congenital abnormality, and who were receiving care at the Professorial Obstetric Unit of the University of Colombo.

A semi-structured interview was conducted by a Registrar-level doctor who was trained to recognise distress and to offer counselling where needed. The women gave written consent to be interviewed. The contact details of the interviewers were given to the women in case they sought help in distress and for further clarifications. We inquired into the responses of the women on hearing the news, the support received from their families, their views on abortion, their experiences in the antenatal period and during labour and their coping strategies.

Approval was obtained from the Ethical Review Committee of the Faculty of Medicine, University of Colombo.

\section{Results}

The characteristics of the women and the abnormality diagnosed are given in Table 1. The psychological reactions and coping strategies of the women are given in Table 2.

The last three women recruited had special arrangements for antenatal care in the gynaecology ward, rather than in the routine antenatal clinic. This was based on comments made by the first seven women who found contact with other women in the routine antenatal clinic painful. These seven women also felt the clinic staff, including doctors, was ill-equipped and ill-informed to deal with their situation. They complained that "routine" antenatal care was inappropriate for them and that the staff asked questions related to fetal well-being, such as about fetal movements, which were inappropriate.

Four required admission during the antenatal period for maternal reasons. They found experiences in the antenatal ward painful. All women said that their husbands were supportive.

Table 1. The characteristics of the women and the anomalies diagnosed

\begin{tabular}{|c|c|c|c|}
\hline \multicolumn{2}{|c|}{$\begin{array}{l}\text { Mother's Living } \\
\text { age children }\end{array}$} & $\begin{array}{c}\text { POG at } \\
\text { diagnosis } \\
\text { (weeks) }\end{array}$ & Diagnosis \\
\hline 22 & 0 & 32 & $\begin{array}{l}\text { Meningomyelocele, } \\
\text { hydrocephalus }\end{array}$ \\
\hline 41 & 1 & 29 & Multiple abnormalities \\
\hline 41 & 0 & 28 & $\begin{array}{l}\text { Univentricular heart, } \\
\text { omphalocele }\end{array}$ \\
\hline 19 & 0 & 26 & Anencephaly \\
\hline 25 & 1 & 30 & $\begin{array}{l}\text { Recurrent ascites despite } \\
\text { repeated drainage }\end{array}$ \\
\hline 30 & 0 & 28 & $\begin{array}{l}\text { Hydrothorax, ascites, } \\
\text { exomphalos }\end{array}$ \\
\hline 28 & 0 & 30 & $\begin{array}{l}\text { Holoprosencephaly with } \\
\text { cyclopia }\end{array}$ \\
\hline 31 & 1 & 27 & Anencephaly \\
\hline 31 & 0 & 31 & Multiple anomalies \\
\hline 30 & 0 & 28 & Pentalogy of Cantrell \\
\hline
\end{tabular}

$\mathrm{POG}=$ period of gestation 
Table 2. Psychological reactions of the women

\begin{tabular}{lc}
\hline Parameter & $\begin{array}{c}\text { Number } \\
(n=10)\end{array}$ \\
\hline $\begin{array}{l}\text { Initial reaction of shock, disbelief, denial, } \\
\text { intense sadness, anxiety and fear }\end{array}$ & 10 \\
Distress about continuing a futile pregnancy & 10 \\
$\begin{array}{l}\text { Felt that knowing the fetus was abnormal } \\
\text { helped prepare for the outcome }\end{array}$ & 8 \\
$\begin{array}{l}\text { Felt they would have preferred not to know } \\
\text { of the anomaly }\end{array}$ & 2 \\
$\begin{array}{l}\text { Delivering in the same labour ward with others } \\
\text { was distressing }\end{array}$ & 10 \\
$\begin{array}{l}\text { Feared delivering in a teaching hospital in } \\
\text { Colombo because "doctors might make the } \\
\text { abnormal baby live" }\end{array}$ & 2 \\
$\begin{array}{l}\text { Focused on healthy children to overcome grief } \\
\text { Engaged in religious rites believed to have } \\
\text { miraculous powers }\end{array}$ & 3 \\
$\begin{array}{l}\text { Hoped religious rites would heal the anomaly } \\
\text { Hoped religious rites would prove the } \\
\text { diagnosis wrong }\end{array}$ & 10 \\
\hline
\end{tabular}

All women felt that termination of pregnancy for lethal congenital abnormalities should be legalised in Sri Lanka. Four stated that they would have certainly opted for termination if the option was available, and felt that it was unjustifiable that they had no legal recourse to it. The other six were unable to say for certain whether they would have opted for termination of pregnancy.

Two women were distressed to such an extent that they required repeated counselling sessions in the Psychological Medicine Unit. One of them, carrying a fetus with hydrocephalus, was told that there may be a possibility that the fetus could live with a shunt. She had in the past had two similar fetuses dying in the neonatal period. This baby was born with dysmorphic features that were not detected prenatally, and died on the second day. The second was carrying a fetus with the pentalogy of Cantrell. On inquiry, we found that the initial counselling for her and the husband was done in the corridor outside the ultrasound room.

\section{Discussion}

All women in this study were distressed by the news of fetal abnormalities and by the fact that they had to continue futile pregnancies. When breaking the news of a LCM, clear information regarding the anomaly and its prognosis are essential to help these families come to terms with it. A common thread of the interviews was that care was provided insensitively and that the doctors were poorly equipped to handle these women and their families. They wished to know more about the anomaly, and contact with knowledgeable staff was inadequate. Staff concentrated mostly on the futility of the pregnancy and on informing that the option of termination was not available.

An arrangement for care that separates them from women carrying 'normal' pregnancies was greatly appreciated by them. This would also enable a doctor who is aware of the condition of the fetus to provide care for the mother. The need for such arrangements is stressed in other studies as well [1]. The majority of the women (eight out of ten) felt that knowing the baby had a major anomaly prepared them for the final outcome. Ultrasound screening for fetal anomalies, despite there being no provision for termination, may be still justified on this basis.

All women relied heavily on religious rites as a coping strategy throughout pregnancy. Their expectations were unreal and they believed that these rites would result in the birth of a normal baby. The dependence on religious rites has not been a finding of note in any of the previous studies, but seems typical of Sri Lankan culture. It is possible that these rites may help these families in the long term bereavement process.

There have been suggestions from other studies that women who have continued such pregnancies would come to terms with it better than women who opted for termination [2]. Continuation of pregnancy may help the women to avoid feelings of guilt, regret and doubt. It is possible that some parents may doubt the accuracy of ultrasound scans on which termination of pregnancy is based, allowing this doubt to weigh on their minds in the future. A woman who is offered termination of pregnancy is also placed in a situation of conflict, having to make a decision on a baby she has developed an intense attachment to. The psychological morbidity of women who undergo termination of pregnancy for fetal abnormality is well documented [4-8]. In one study, 17\% of a group of women who were assessed 2 months after termination of pregnancy for fetal abnormality were found to have developed major depression [6]. This is contrary to the popular belief that the problems of a pregnancy complicated by a LCM would end with its termination and that it should be offered as a matter of course.

All mothers in the group were certain that the option of a termination should be available to women in their situation. However, six were uncertain as to what course of action they would have taken in case it was available.

\section{Conclusions}

Women with pregnancies complicated by LCMs would require continued psychological support. Wherever possible, it is best that they receive their care with minimal contact with women with 'normal' pregnancies and that the care is provided by professionals who are aware of the fetal anomaly and its prognosis. All the women questioned felt that care was given to them insensitively. 
Abortion laws may need to be amended to accommodate LCMs and some women in the study said they would have taken that option if it were available. However, the option of continuing the pregnancy must also be offered. Our findings suggest that factors associated with continuation of pregnancy may provide a basis for the long term psychological well-being of these women.

\section{References}

1. Chitty LS, Barnes CA, Berry C. Continuing with pregnancy after a diagnosis of lethal abnormality: experience of five couples and recommendations for management. British Medical Journal 1996; 313: 478 80 .

2. Watkins D. An alternative to termination of pregnancy. The Practitioner 1989; 233: 990-2.

3. Redlinger-Grosse K, Bernhardt BA, Berg K, Muenke M, Biesecker BB. The decision to continue: the experiences and needs of parents who receive a prenatal diagnosis of holoprosencephaly. American Journal of Medical Genetics 2002; 112: 369-78.

4. Hunfield JAM, Wladimiroff JW, Passchier J, Venema Van Uden MU, Frets PG, et al. Emotional reactions in women in late pregnancy ( 24 weeks or longer) following a prenatal diagnosis of a severe lethal congenital malformation. Prenatal Diagnosis 1993; 13: 864-7.

5. Zeanah CH, Dailey JV, Rosenblatt MJ, Saller DNJr. Do women grieve after terminating pregnancies because of fetal anomalies? A controlled investigation. Obstetrics and Gynecology 1993; 82: 270-5.

6. Iles S, Gath D. Psychiatric outcome of termination of pregnancy for foetal abnormality. Psychological Medicine 1993; 23: 407-13.

7. Statham H, Solomou W, Chitty L. Prenatal diagnosis of fetal abnormality: psychological effects on women in lowrisk pregnancies. Baillieres Best Practice and Research. Clinical Obstetrics and Gynaecology 2000; 14: 731-47.

8. Leithner K, Maar A, Fischer-Kern M, Hilger E, LofflerStastka H, Ponocny-Seliger E. Ultrasound in Obstetrics and Gynecology 2004; 23: 240-6. 